\title{
Fractional-order PID controller for permanent magnet DC motor based on PSO algorithm
}

Fadhil A. Hasan, Lina J. Rashad

Department of Electrical Engineering, University of Technology, Iraq

\begin{tabular}{|c|c|}
\hline Article Info & ABSTRACT \\
\hline Article history: & \multirow{10}{*}{$\begin{array}{l}\text { This paper proposes the fractional-order proportional integral derivative } \\
\text { (FOPID) controller, as a speed controller for permanent magnet direct current } \\
\text { (PMDC) motor, instead of the traditional integer-order PID controller. The } \\
\text { FOPID controller is the general form of the integer-order PID controllers, } \\
\text { which found wide applications in all engineering fields. In this work a hybrid } \\
\text { M-file and SIMULINK program is developed to simulate the overall system, } \\
\text { the FOPID controller has five associated parameters. The optimum values of } \\
\text { those parameters are found out by using particle swarm optimization } \\
\text { technique. Simulation results show excellent command speeds tracking and } \\
\text { superior dynamic response in conjunction with that of the integer-order PID } \\
\text { controller. The proposed controller shows a high ability to overcome any } \\
\text { external disturbance the system may be exposed; also, it performs a high } \\
\text { degree of robustness to control the system in motoring and regenerative } \\
\text { operating modes. }\end{array}$} \\
\hline Received Dec 24, 2018 & \\
\hline & \\
\hline Accepted Mar 10, 2019 & \\
\hline Keywords: & \\
\hline Fractional-order controller & \\
\hline Particle swarm optimization & \\
\hline Permanent magnet DC motor & \\
\hline PID controller & \\
\hline Tuning parameters of PID & \\
\hline
\end{tabular}

Copyright (C) 2019 Institute of Advanced Engineering and Science. All rights reserved.

\section{Corresponding Author:}

Fadhil A. Hasan,

Department of Electrical Engineering,

University of Technology,

Baghdad, Iraq.

Email: Fadhil.a.hassan@gmail.com

\section{INTRODUCTION}

Fractional Order Proportional Integral Derivative controller (FOPID) is a most powerful type of PID controller in which the order of derivative and integral are fractional $\left(\mathrm{PI}^{\lambda} \mathrm{D}^{\gamma}\right)$ rather than integer number. It offers an effective tool to descript the inheriting memory features of various articles. This is a great property of this controller in conjunction with ordinary PID controller; actually, this effect is not considered [1].

In addition, the fractional order controller is more convenient than integer-order models in the control of dynamical systems. Another advantage is the fact that fractional order controllers are insensitive to parameters variation of the system and also the controller parameters [2]. The FOPID control system presents a high degree of stiffness to overcome any disturbance or load variation, also its time and frequency responses can be adjusted efficiently as compared with the model predictive controller [3]. The fractional order controller (FOC) has already come in beneficial in many attractive engineering areas such as electronics, robotics, bioengineering, control theory and signal processing [4]. Concepcion A. M. et al, presented a self - tuning and auto-tuning to estimate the controller parameters of the FOPID controller, the method gave robust and more reliable control [5]. Rinu P. S. et al presented the Nelder-mead method and the ABC (artificial bee colony algorithm) to optimize the five parameters of Fractional-order PID controller [6]. Hassan N.A et al presented Pareto method for numerical optimization of the fractional order PID to give an estimation of the controller parameter to meet the engineering specification needs, and compared results by traditional PID controller [7].

From the literature, it can be noted that there are no previous attempts to investigate the non-linear behavior of the PMDC by parameters variation during operation. The resistance of the armature windings is 
one of the main parameter whose has non-linear behavior due to the generated and rised heat in the windings by repetition of operation, which makes the system non-linear in nature. This paper proposes the use of the FOPID controller as a nonlinear controller of PMDC by taking into consideration the nonlinearty behavior of armature resistance, which is the main contribution of this work. This paper exploits the advanced features of the FO controller as an adjustable speed driver of a PMDC. The dominant parameters, of the proposed controller, are tuned by using the Particle Swarm Optimization (PSO) technique. The results of the proposed controller will be compared with that of the traditional integer-order PID controller.

\section{THE DIFFER-INTEGRAL AND FRACTIONAL ORDER SYSTEMS}

The fractional analysis is the sector that deals with the ability of powering the integral and differential operators by fraction number instead of an integer number. Mathematically, the fractional order integral and derivative can be defined in numerous ways. The general presentation of the differ-integrator operator is:

$$
{ }_{a}^{c} D_{t}^{q} f(t)=\frac{d^{q} f(t)}{[d(1-a)]^{q}}
$$

Where "q" represents the real order of the differ-integral, "t" is variation domain, and "a" is the lower limit. In the Nineteen Sixties, Caputo presented a popular form to calculate the differ-integral. A fractional derivative of order " $\lambda$ " with variation in " $t$ " domain and with initial condition $t=0$ is become as [8]-[10]:

$$
\begin{aligned}
& { }_{0}^{j} D_{t}^{\lambda} y(t)=\frac{1}{\Gamma(1-\delta)} \int_{0}^{t} \frac{y^{(m+1)}(\tau) d \tau}{(t-\tau)^{\delta}} \\
& (\gamma=m+\delta, m \in Z, 0<\delta \leq 1)
\end{aligned}
$$
with $-\gamma$ order:

Where $\Gamma(\mathrm{z})$ is Euler's Gamma function. When $\gamma<0$, then represent a fractional integral operator

$$
{ }_{0}^{j} I_{t}^{-\gamma} y(t)={ }_{0}^{j} D_{t}^{\gamma} y(t)=\frac{1}{\Gamma(-\gamma)} \int_{0}^{t} \frac{y(\tau) d \tau}{(t-\tau)^{1+\gamma}},(\gamma<0)
$$

One wonderful benefit of using this definition is presenting easy explanations to initial and boundary conditions, in which the derivation of any constant value equals to zero. In the time domain, an nterm of fractional order differential equations are present the fractional order system:

$$
a_{n} D^{B_{n}} y(t)+a_{n-1} D^{B_{n-1}} y(t)+a_{1} D^{B_{1}} y(t)+a_{0} D^{B_{1}} y(t)=u(t)
$$

Where $\mathrm{D}^{\lambda}={ }_{0}^{2} \mathrm{D}_{\mathrm{t}}^{\lambda}$ is the Caputo's fractional derivation of order " $\lambda$ ”.

Tacking the Laplace transform to (4) the fractional order transfer function can be obtained,

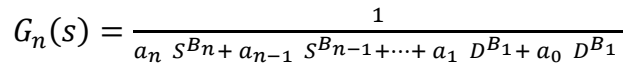

Where; $B_{k}=(k=0,1, \ldots, n)$ is a real number, $\beta_{n}>\beta_{n-1}>\cdots>\beta_{1}>\beta_{0}>0$ and $a_{k}=$ $(\mathrm{k}=0,1, \ldots, \mathrm{n})$ is constant.

The fractional derivative in Laplace form is:

$$
\int_{0}^{\infty} e^{-s t} D^{\gamma} y(t) d t=S^{\gamma} Y(s)-\sum_{k=0}^{m} S^{\gamma-\mathrm{k}-1} y^{k}(\theta)
$$

The summation in the right-hand of (6) must be canceled if $\gamma<0$.

\section{FRACTIONAL ORDER CONTROL}

The PID controller is a universal controller based on a closed-loop mechanism has widespread applications in industrials controlling systems. The PID controller attempts to correct the error between an actual system feedback and a reference set-point by evaluating and then outputting a corrective action that could adjust the system according to that. The transfer function of an ordinary PID controller is:

Fractional-order PID controller for permanent magnet DC motor based on PSO ... (Fadhil A. Hasan) 


$$
G c(s)=K_{p}\left(1+\frac{s^{-1}}{T_{i}}+T_{d} s\right)
$$

The algorithm of the PID controller includes three independent parameters; the Proportion gain (K p) and the Integral and Derivative time constants ( $\mathrm{Ti} \& \mathrm{Td}$ ) respectively. $\mathrm{K}$ p evaluates the response to the instant error, while $\left(\frac{K_{p}}{T_{i}}\right)$ estimates the integral reaction according to the summation of recent errors and $\left(\mathrm{K}_{\mathrm{p}} \mathrm{T}_{\mathrm{d}}\right)$ drive the derivative response according to the rate of changing errors. The algebraic summation of these actions is utilized to adjust the system by an appropriate controlling signal.

In fact, the real controlled systems have fractional nature in general. Nevertheless, the fractionality could be small. Broadly, the approximate integer-order of the fractional system leads to a serious difference between the actual system and the mathematical model. Because of the fractional-order differential equations is a difficult calculus procedure then the integer-order models are used widely. The generalized form of the PID-controller, which also known as $\mathrm{PI}^{\lambda} \mathrm{D}^{\gamma}$ controllers, is as follow:

Where, $\lambda$ and $\gamma$ are the integrator and differentiator orders respectively.

Then,

$$
\mathrm{G}_{\mathrm{C}}(\mathrm{s})=\mathrm{K}_{\mathrm{p}}\left(1+\frac{\mathrm{s}^{-\lambda}}{\mathrm{T}_{\mathrm{i}}}+\mathrm{T}_{\mathrm{d}} \mathrm{s}^{\gamma}\right),(\lambda, \gamma>0)
$$

The time domain output is:

$$
u(t)=K_{p} e(t)+K_{i} D^{-\lambda} e(t)+K_{d} D^{\gamma} e(t)
$$

Where, $K_{i}=\frac{K_{p}}{T_{i}}$ and $K_{d}=K_{p} T_{d}$.

In other words, the fractional order $\mathrm{PI}^{\lambda} \mathrm{D}^{\gamma}$ controller is the global form of the conventional PID controller, which is a particular case controller. As shown in Figure 1, the $\mathrm{PI}^{\lambda} \mathrm{D}^{\gamma}$ controller expands the conventional PID controller and extends it from point to surface. This extension increases the flexibility to controller adjustment, and performs more accurate response of the actual system. [8], [9].

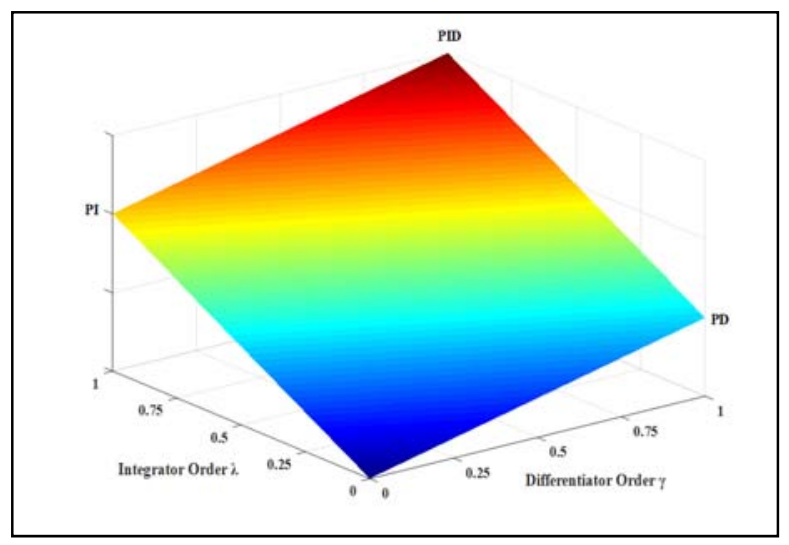

Figure1. Extend the PID control from point to surface

\section{MATHEMATICAL MODEL OF PMDC MOTOR}

Permanent magnet motors are used in various industrial applications because of their reliability, controllability, don't need external excitation, and inexpensive [11], [12]. Permanent magnet DC motor is found in several low and high-power industrial applications. The equivalent circuit of the PMDC motor is shown in Figure 2, from which (10), (11) and (12) can be written. 


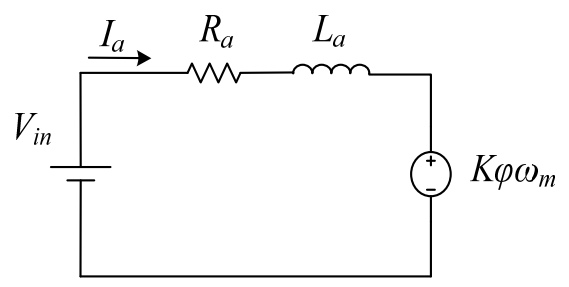

Figure 2. The equivalent circuit of a permanent magnet DC machine

$$
\begin{aligned}
& V_{i n}=I_{a} R_{a}+L_{a} \frac{d I_{a}}{d t}+K \varphi \omega_{m} \\
& T_{e}=K_{\varphi} I_{a} \\
& J \frac{d \omega_{m}}{d t}=T_{e}+T_{L}+B_{m} \omega_{m}
\end{aligned}
$$

Where: Vin the supply voltage (V), Ia current of the armature (A), $\varphi$ is the pole magnetic flux (Wb), $\left(\mathrm{R}_{\mathrm{a}}\right)$ resistance of the armature $(\Omega),\left(\mathrm{L}_{\mathrm{a}}\right)$ inductance of the armature $(\mathrm{H}), \mathrm{K}$ machine constant (V.s/rad), $\omega \mathrm{m}$ rotor speed $(\mathrm{rad} / \mathrm{s})$, Te developed torque $(\mathrm{Nm})$, TL Load torque $(\mathrm{Nm}), \mathrm{Bm}$ damping coefficient (N.m.s/rad), and $\mathrm{J}$ inertia constant (kg.m2). Clearly, from (10), the armature resistance and inductance are the dominant parameters which judged the transient and steady state response. The variation of armature resistance is taken periodically about $10 \%$ of its cold value as shown in Figure 3.

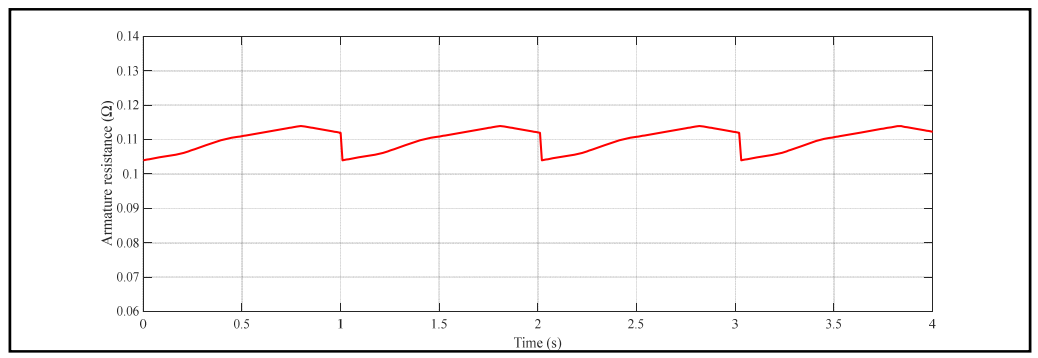

Figure 3. The variation of armature resistance

\section{PARTICLE SWARM OPTIMIZATION (PSO)}

The particle swarm optimization is firstly presented by James and Russell in 1995[13], a seeking algorithm having a random probability distribution or pattern inspiring by a community habit of the flock of birds [14], it is one of the powerful optimization techniques. It has been observed to be strong in nonlinearly optimization issues [15], [16]. An improved PSO was presented in 1998 to upgrade the performance of the conventional PSO. An addition coefficient known as inertia weight is introduced [14]. PSO is a set of rules associates both cognition and public collaboration of birds.

In this method, each bird "particle" searches for the optimum position by updates its location within the swarm, according to the advantage of its memory of the best position and knowing about the global best location [15]. The optimization procedure obtained by (13) and (14).

$$
\begin{aligned}
& v_{i}(k+1)=W v_{i}(k)+C_{1} R_{1}\left(g_{b e s t}-x_{i}(k)\right)+C_{2} R_{2}\left(p_{b e s t}-x_{i}(k)\right) \\
& x_{i}(k+1)=x_{i}(k)+v_{i}(k+1) \\
& i=1,2, \ldots, n
\end{aligned}
$$

Where: vi is the ith particle velocity, $\mathrm{xi}$ is the ith particle position, $\mathrm{k}$ iteration number, $\mathrm{C} 1, \mathrm{C} 2 \mathrm{known}$ as the cognitive and social coefficients, w inertia weight factor, R1, R2 random variables of from 0 to 1 , $\mathrm{p}_{\text {best,i }}$ individual best position of particle $\mathrm{i}$, g $\mathrm{g}_{\text {best }}$ best global position of all the particles in the swarm, and $\mathrm{n}$ number of birds (particles).

If the condition in (15) is met, then the position is updated through (16):

$$
f\left(x_{i k}\right)<f\left(p_{\text {best }}\right)
$$

Fractional-order PID controller for permanent magnet DC motor based on PSO ... (Fadhil A. Hasan) 


$$
p_{\text {best }}=x_{i k}
$$

Where: f perform the minimization objective fitness function. The flowchart of the PSO algorithm is illustrated in Figure 4.

Usually, in optimization techniques, there are several fitness criteria to evaluate system performance as such as Integral Absolute Errors (IAE), the Integral of Square Errors (ISE), and Integral of Time Square Errors (ITSE). These performance criteria are inclusive the overshoot, rising time, settled time and steadystate error. In addition, it has been specified the optimization process and the tightness of the driving system [17]. In this work the ITSE fitness function, illustrated in (17), is used as the performance criteria of the output response of the system:

$$
\text { ITSE }=\int_{0}^{\infty} t e^{2}(t) \cdot d t
$$

The block diagram of the optimization process for FOPID-PSO system is shown in Figure 5. A MATLAB program is developed to find out the optimal values of the five controller parameters $\lambda, \gamma, K_{p}, T_{i}$, and $\mathrm{T}_{\mathrm{d}}$. A minimization algorithm is applied in the search domain of the particles position and velocity, the optimum values of the FOPID controller are obtained in 100 iterations as shown in Figure 6.



Figure 4. Flow chart of the PSO algorithm

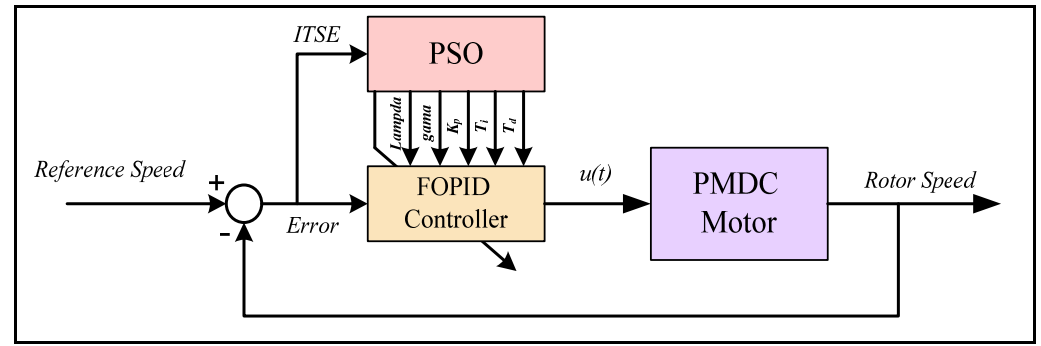

Figure 5. The block diagram of the optimized FOPID controller 


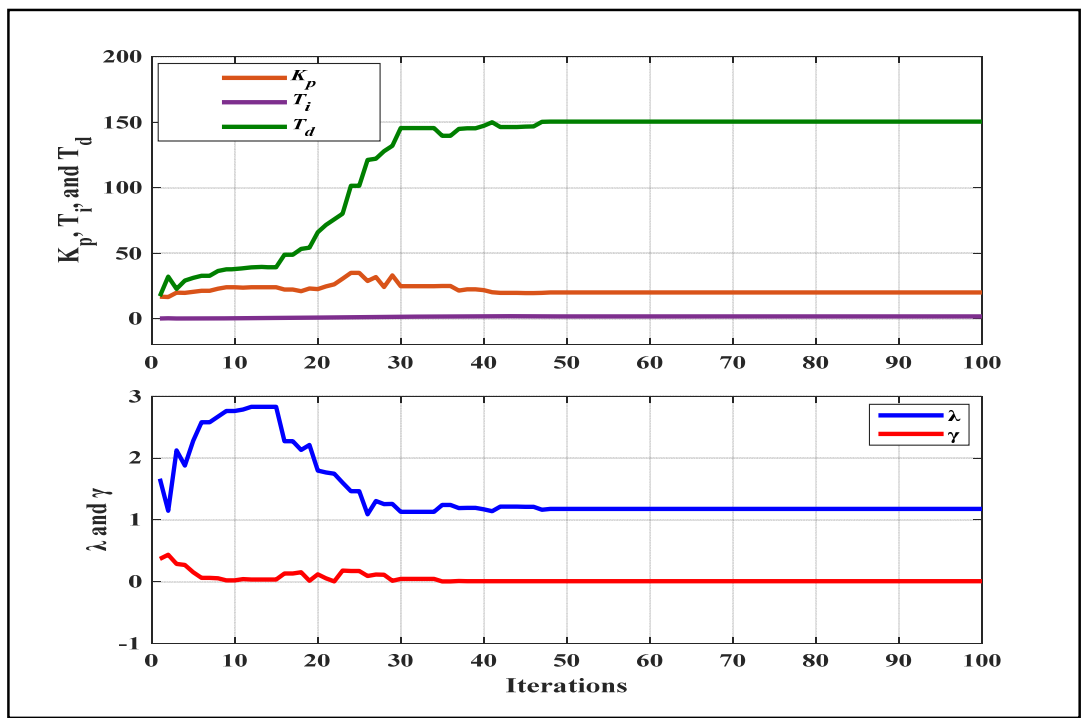

Figure 6. The controller parameters during the optimization process

\section{SIMULATION RESULTS}

The overall system simulation is shown in Figure 7. A MATLAB-SIMULINK model is designed; a built-in M-file is developed to calculate the fractional order integral and derivative in a specific sampling time. The speed, torque, and armature current response to rated speed command of the PMDC motor under the full-load condition are depicted in Figure 8. Also, the response of the system to a stair steps input of different speed commands under full-load condition can be shown in Figure 9.

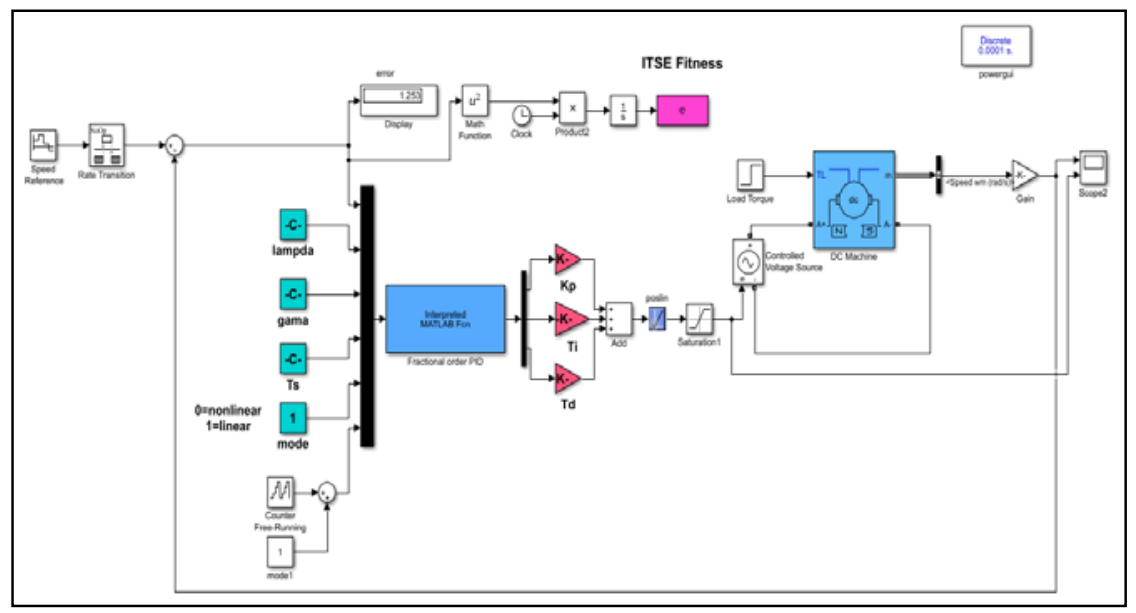

Figure 7. The overall system simulation 

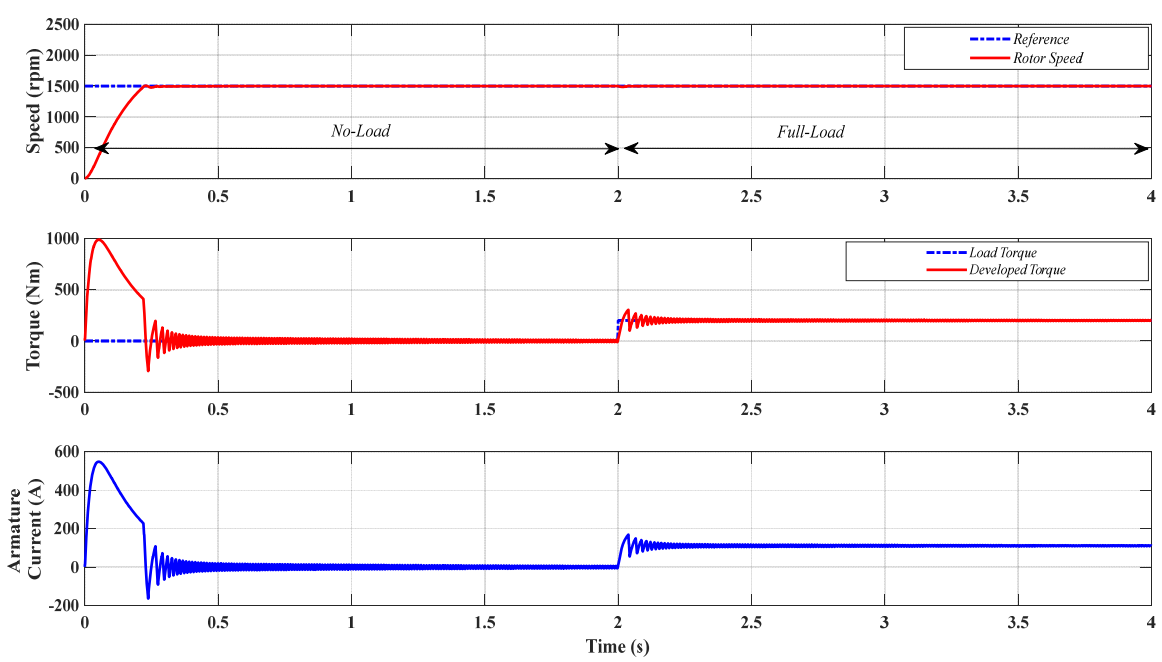

Figure 8. Rated speed and full-load response of the FOPID controller


Figure 9. Stair response of the FOPID controller

In order to realize the features of the proposed controller, a comparison performance is investigated in conjunction with the traditional integer-order PID controller. The performance for both rated of speed and stair commands are shown in Figure 10 and Figure 11. Moreover, the robustness of the proposed controller can be proven in four-quadrant operation conditions of the PMDC motor. Positive and negative speed commands are applied to the motor under various positive and negative load torques. The speed, torque, and current performance of the system for this operation are shown in Figure 12. 

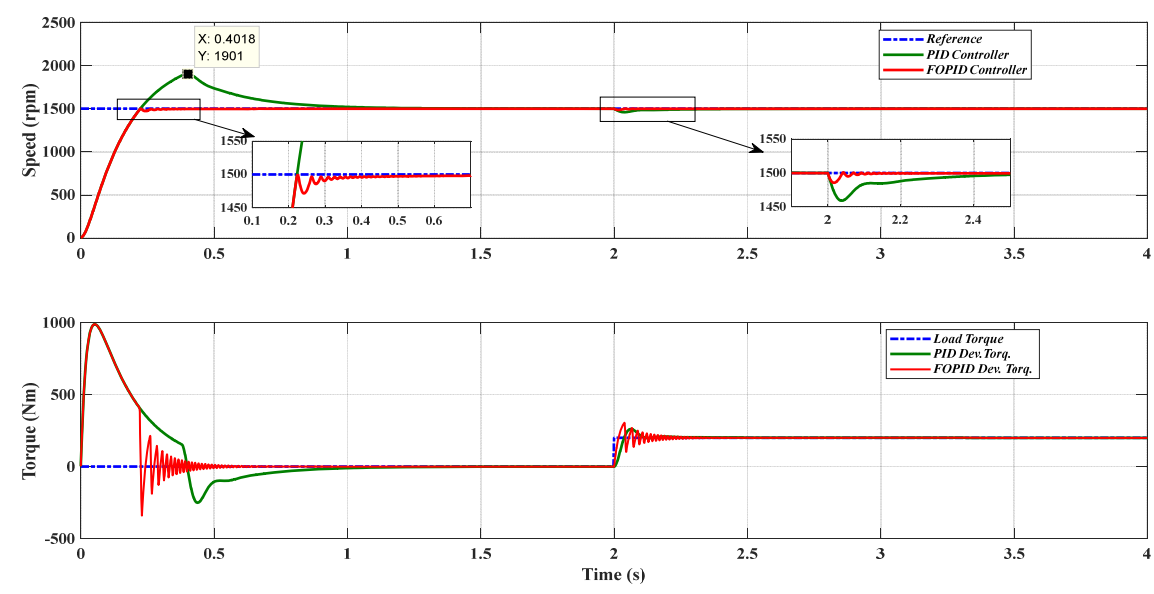

Figure 10. A comparison performance of rated speed command
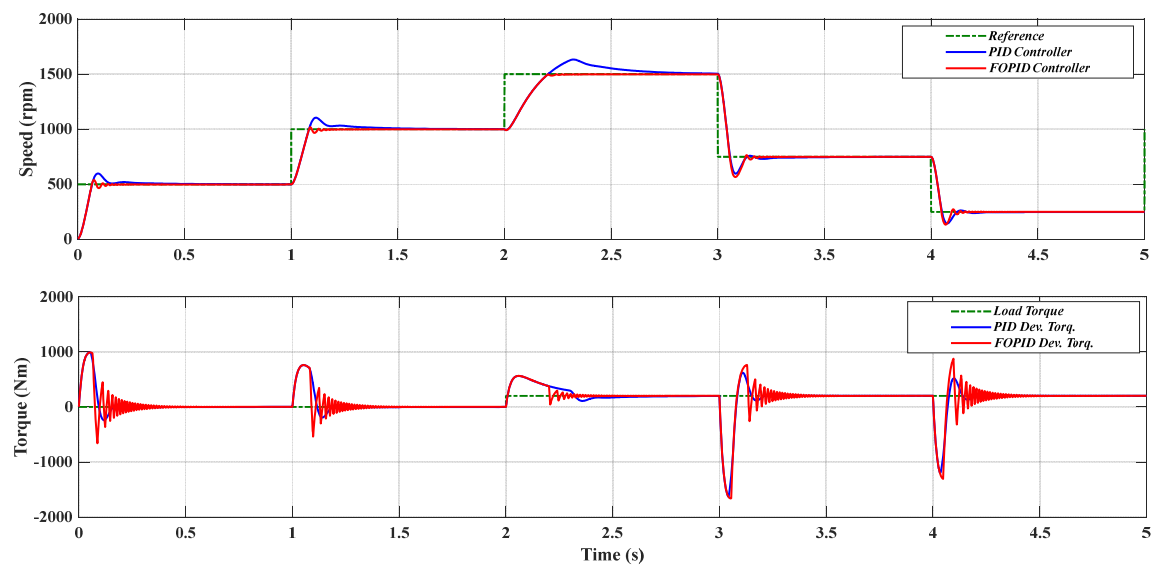

Figure11. A comparison performance of different speed command
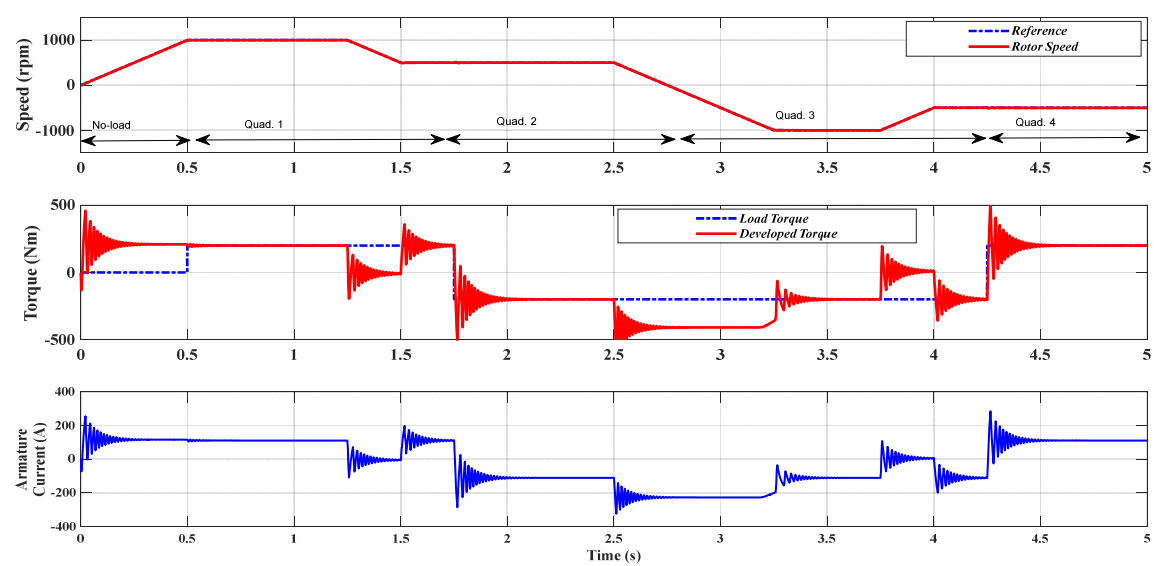

Figure 12. Four-quadrant operation 


\section{DISCUSSION}

Obviously, the performance of the PMDC under the action of the FOPID controller shows an excellent response, for both of rated step and stair steps input commands, although the non-linear behavior of the msystem. Figure 8 and Figure 9 show accurate speed tracking for at no-load and full-load conditions, the performance shows a superior dynamic response. Also, the comparison investigation, between the fractionalorder and the integer-order PID controllers, shows eminent features of the proposed controller. Figure 10 and Figure 11 illustrate the dynamic response (maximum overshoot, rise time, settling time, and steady-state error) to the rated step input of the integer-order PID controller about $26 \%, 0.23 \mathrm{~s}, 1 \mathrm{~s}$, and $1.3 \%$ respectively. Whereas, the dynamic responses of the FOPID controller are: $1.7 \%, 0.23 \mathrm{~s}, 0.37 \mathrm{~s}$, and $0.2 \%$ respectively. In addition, the starting current period of the FOPID is about half of that of the integer-order PID, this will reduce the winding temperature due to multi-starting operation. Moreover, the transient response of the traditional PID controller due to full-load disturbance shows: maximum overshoot $=2.7 \%$ and settling time $=$ $0.5 \mathrm{~s}$. Whilst, the FOPID controller shows: maximum overshoot $=0.7 \%$ and settling time $=0.25 \mathrm{~s}$. Finally, the four-quadrant operation of the PMDC motor in Figure 12 shows a high degree of robustness for different positive and negative speed and load torque. A superior speed tracking is performed under both of delivered and consumed power modes.

\section{CONCLUSION}

This paper proposed the FOPID controller, instead of the integer-order PID controller, to control the speed of the PMDC with considering the non-linear behavior of armature resistance. Both of the fractionalorder and the integer-order PID controllers are simulated, and the responses of them are investigated under different operating conditions. Simulation results show excellent command speeds tracking and superior dynamic response although the variation of system parameter. The proposed controller shows a high ability to overcome any internal or external disturbance the system may be exposed; also, it performs a high degree of robustness to control the system in motoring and regenerative operating modes.

\section{REFERENCES}

[1] J. Zhong and L. Li, "Tuning Fractional-Order $\mathrm{PI}^{\lambda} \mathrm{D}^{\mu}$ Controllers for a Solid-Core Magnetic Bearing System," in IEEE Transactions on Control Systems Technology, vol. 23, no. 4, pp. 1648-1656, July 2015.

[2] A. S. Chopade, S. W. Khubalkar, A. S. Junghare, M. V. Aware and S. Das, "Design and implementation of digital fractional order PID controller using optimal pole-zero approximation method for magnetic levitation system," in IEEE/CAA Journal of Automatica Sinica, vol. 5, no. 5, pp. 977-989, September 2018.

[3] K. Nosrati, H. R. Mansouri and H. Saboori, "Fractional-order PID controller design of frequency deviation in a hybrid renewable energy generation and storage system," in CIRED - Open Access Proceedings Journal, vol. 2017, no. 1, pp. 1148-1152, 102017.

[4] Rinu P. S. and Ramesh b. N., "Design and Analysis of Optimal Fractional-Order PID Controller," International Journal of Applied Engineering Research, ISSN 0973-4562 vol. 10 no. 30, 2015.

[5] J. Viola, L. Angel and J. M. Sebastian, "Design and robust performance evaluation of a fractional order PID controller applied to a DC motor," in IEEE/CAA Journal of Automatica Sinica, vol. 4, no. 2, pp. 304-314, April 2017.

[6] L. Lu, S. Liang, D. Yuewei, L. Chenglin and Q. Zhidong, "Improved quantum bacterial foraging algorithm for tuning parameters of fractional-order PID controller," in Journal of Systems Engineering and Electronics, vol. 29, no. 1, pp. 166-175, Feb. 2018.

[7] C. Jauregui, M. Duarte Mermoud, G. Lefranc, R. Orostica, J. C. Travieso Torres and O. Beytia, "Conical Tank Level Control with Fractional PID," in IEEE Latin America Transactions, vol. 14, no. 6, pp. 2598-2604, June 2016.

[8] T. Mahto and V. Mukherjee, "Fractional order fuzzy PID controller for wind energy-based hybrid power system using quasi-oppositional harmony search algorithm," in IET Generation, Transmission \& Distribution, vol. 11, no. 13, pp. 3299-3309, 792017.

[9] P. Bhaskara Prasad, M. Padma Lalitha, and B. Sarvesh, "Fractional Order PID Controlled Cascaded Re-boost Seven Level Inverter Fed Induction Motor System with Enhanced Response," International Journal of Power Electronics and Drive System (IJPEDS), Vol. 9, No. 4, pp. 1784-1791, December 2018.

[10] Deepti Yadav, Arunima Verma, "Comperative Performance Analysis of PMSM Drive Using MPSO and ACO Techniques," International Journal of Power Electronics and Drive System (IJPEDS), Vol. 9, No. 4, pp. 1510-1522, December 2018.

[11] M. Rezaei Estakhrouiyeh, M. Vali and A. Gharaveisi, "Application of fractional order iterative learning controller for a type of batch bioreactor," in IET Control Theory \& Applications, vol. 10, no. 12, pp. 1374-1383, 2016.

[12] S. Folea, C. I. Muresan, R. De Keyser and C. M. Ionescu, "Theoretical Analysis and Experimental Validation of a Simplified Fractional Order Controller for a Magnetic Levitation System," in IEEE Transactions on Control Systems Technology, vol. 24, no. 2, pp. 756-763, March 2016.

[13] James K. and Russell E., "Particle Swarm Optimization", IEEE International conference, 4, 1995.

Int J Pow Elec \& Dri Syst Vol. 10, No. 4, Dec 2019 : 1724 - 1733 
[14] Y. Shi and R. Eberhart, "A modified particle swarm optimizer," 1998 IEEE International Conference on Evolutionary Computation Proceedings. IEEE World Congress on Computational Intelligence (Cat. No.98TH8360), Anchorage, AK, USA, pp. 69-73, 1998.

[15] Mahmud I. S., Lee F. T. and Moey L. K., "Tuning of PID Controller Using Particle Swarm Optimization (PSO)", Proceeding of the International Conference on Advanced Science, Engineering and Information Technology, Malaysia, 2011.

[16] A. Soundarrajan, S. Sumathi, and C. Sundar, "Particle Swarm Optimization Based LFC and AVR of Autonomous Power Generating System," IAENG International Journal of Computer Science, Vol. 37, No. 1, 2010.

[17] Ahmed S. Al-Araji andAhmed I. Abdulkareem, "A Nonlinear Neural Controller Design for the Single Axis Magnetic Ball Levitation System Based on Slice Genetic Algorithm," Eng. And Tech. Journal, vol. 34, part (A), 2012.

\section{BIOGRAPHIES OF AUTHORS}



Fadhil A. Hasan was born in Baghdad, Iraq in February 17, 1970. He received the B.Sc. from the university of Al-mustansiryah, Baghdad, Iraq, in 1991, in electrical engineering. And he received the M.Sc. and Ph.D. degrees from University of Technology, in 2008 and 2017 respectively, in electrical machine and control engineering. In 2008, he joined the department of electrical engineering at university of technology, Baghdad, in Iraq, as an Asst. Lecturer. Currently he is a lecturer in the department of electrical engineering at university of technology, Baghdad, in Iraq. $\mathrm{He}$ has published over 16 refereed journal and conference papers in the areas of induction heating, control systems, power electronics and electrical machine.

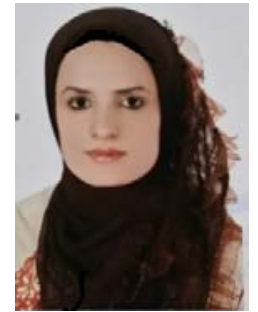

Lina J. Rashad was born in Baghdad, Iraq in May 7, 1983. She received the B.Sc., M.Sc. and Ph.D. degrees from University of Technology, Baghdad, Iraq, in 2006, 2008 and 2016 respectively. In 2008, she joined the department of electrical engineering at university of technology, Baghdad, in Iraq, as an Asst. Lecturer. Currently she is a lecturer in the department of electrical engineering at university of technology, Baghdad, in Iraq. She has published over 15 refereed journal and conference papers in the areas of control systems, power electronics and electrical machine. 